\title{
Understanding Chinese Culture and Communication: The Yin Yang Approach ${ }^{1}$
}

\author{
Tony Fang \\ Stockholm University
}

\section{INTRODUCTION}

China is emerging as a world economic superpower in the age of globalization, foreign direct investment (FDI), and Internet. China has been for many years rated as the most attractive destination for FDI by CEOs and CFOs from around the world (see A.T. Kearney Investor Confidence Index for miscellaneous years). Many share the assertion of Charles Browne, President of Du Pont China, that "If you go to our headquarters and ask which region we are concentrating on, the answer is that we are focused on China, China, China” (Fernandez \& Underwood, 2006: xiv). With nearly 600,000 foreign-invested companies including over 400 of the Fortune 500 global firms operating on Chinese soil (Fang, Zhao, \& Worm, 2008) China is undisputedly one of the world's most competitive marketplaces. As Schlevogt (2002: 18) observed: "China is the ultimate test ground for leadership skills and a company's ability to excel in other nonstructured situations... If you can make it here, you can make it anywhere!” Research shows that an in-depth understanding of Chinese culture is key to success in the Chinese market in particular and in the relationships with China in general (Chen, 2001; Child, 1990; Fang, 1999; Tung, Worm, \& Fang, 2008; Fernandez \& Underwood, 2006).

China is one of the world's oldest civilizations with a splendid culture. But what is the uniqueness of Chinese culture that transcends the Chinese society from its "blue gowns" and "bound feet" times (Little, 1902) to today's China with increasingly sophisticated information technology and with popular TV shows such as “Super Girls” (超女 Chaonü) and “You are the One” (非诚勿扰 Fei cheng wu rao) followed live by tens of millions of Chinese fans? What is the same uniqueness of Chinese culture that has contributed to making China's market economy differ from Western market economy in the same way Chinese Communism differs from the former Soviet (or Eastern Bloc) Communism?

Proverbs and social axioms (Leung \& Bond, 2004) manifest our cultures. The Chinese nation's wisdom and personality have been crystalized, at least in part, into the numerous Chinese proverbs handed down generation after generation. If asked to select one Chinese proverb to illustrate, in generalized terms, the uniqueness of Chinese culture and how Chinese people behave in various situations I would select this one: “The old man lost his horse, but who knows if this is a bad luck” (“塞 翁失马, 焉知非福”: “Sai weng shi ma, yan zhi fei fu”, see BOX 1).

\footnotetext{
${ }^{1}$ Fang, T. (2014). Understanding Chinese culture and communication: The Yin Yang approach. Book chapter in Global Leadership Practices, Edited by: Bettina Gehrke \& Marie-Therese Claes, pp. 171-187. London: Palgrave Macmillan.
} 


\title{
BOX 1 "The old man lost his horse, but who knows if this is a bad luck"
}

\begin{abstract}
Once upon a time there was an old man who lived with his son in a small remote mountainous village. The family was poor but they had a lovely horse and a peaceful life. One day the horse unfortunately strayed off. The neighbours all came and said "Sorry, old man; what bad luck you've got.” But the old man said: “What makes you believe this is a bad luck?” Several months later, the disappeared horse all of a sudden came home together with a number of beautiful female wild horses. Then, the neighbours all came to congratulate on the old man's good luck. But the old man said: "What makes you believe this is a good luck?" Now the family had got a number of horses, the son took to riding one of the female wild horses and as a result broke his leg; he became handicapped because of this accident. Once again all the neighbours came to show their sympathy with the family's bad luck. But once again the old man was asking why his neighbours would believe this is a bad luck. A year later, a war broke out; the emperor's army came to recruit all the young males in the village to go to war. Because the son was lame he was except from going to war while all other young males left the village and never returned. The son who girls earlier didn't want to go out with turned out to be the only young man available in the village. He was now able to go out, got married, and become father to many lovely children. This small society survived and the family's name carried on from generation to generation.
\end{abstract}

The story "The old man lost his horse..." is a telling example of the Chinese mental world that is essentially paradoxical and dynamic. Questions like “Good luck or bad luck?” "Yes or No?” “True or false?" must be the most difficult questions for the Chinese to answer. Such "either/or" questioning may fit with western notions of clarity, consistency, and parsimony but it has little chance to capture the Chinese "tolerance of ambiguity, inconsistency, and paradox" (Fletcher \& Fang, 2006: 434). For the Chinese, life is a play (人生如戏: ren sheng ru xi), everything is a game, and nothing is absolute. The Chinese believe that not only the positives and the negatives can coexist but they can give rise to each other and transform into each other given situation, context, and time.

In cross-cultural literature many seek to understand Chinese culture and behaviour through a polarized "either/or" approach. Thus, for example, Chinese culture is theorized as a collectivist culture (e.g, Hofstede, 1980, 1991, 2001) and Chinese communication as manifestation of traditional Confucian values (e.g., Gao, Ting-Toomey, \& Gudykunst, 1996). Similarly, in cross-cultural negotiation research, scholars attempt to decode Chinese negotiating style by focusing on one of the following perspectives: political, cultural, and strategic perspectives (see Fang, 1999 for a comprehensive review). Although the "either/or" approach has generated many powerful models our understanding remains static, segmented and piecemeal.

China is a large country with a 9.6 million skm land area and a 1.4 billion population consisting of people from 56 ethnic groups. Even today under the one-child-per-family policy China's population still 
grows by about 7 million per year. The complexity and richness of China and Chinese culture is among the most striking impressions shared by foreign expatriates in China. One popular saying among foreign diplomatic and business communities in China is as follows:

"We say if you come to China for one week, you feel you can write a book; for one month, an article; but for more than six months, you can pen nothing" (see Note 1)

Seeking to understand China with the polarized methodology we will most probably discover things in China that we want to discover. But the longer we live in China the less we remain confident about our original discovery. As time passes we will increasingly realize that the opposite picture is also true in the vast dynamic Chinese reality. We eventually end up figuring out that China is a land of "millions of truth" (Jakobson, 2001) and Chinese culture can hardly be framed by the "either/or" paradigm. The Chinese are both collectivist and individualist, both traditional and modern, both longterm and short-term, both reserved and expressive, and both Communist and Capitalist, all depending on situation, context, and time. Even in the height of the Cold War, China stayed away from both the United States and Soviet Union (J. Chen, 2001).

Understanding Chinese culture demands and deserves an innovative approach if one wants to capture its essence in a fuller and more holistic way. One useful approach that can help us to shed light on Chinese culture's “millions of truth” is Yin Yang. The purpose of this chapter is to introduce the Yin Yang approach to understand Chinese culture and communication. In the remainder of this text I first discuss what Yin Yang means and how culture can be studied through the Yin Yang perspective. Then, I discuss Chinese culture and Chinese communication characteristics through the lens of Yin Yang. Finally, I conclude the chapter by discussing managerial implications and future research.

\section{YIN YANG}

The Yin Yang symbol (see Box 2) is probably the most well-known symbol in East Asia (Cooper, 1990). Yin Yang is an ancient Chinese philosophical thinking and a holistic, dynamic, and dialectical world view, methodology, and life wisdom (M.-J. Chen, 2001, 2002; Fang, 2003, 2005-2006, 2012a,b; Li, 1998, 2008; Peng \& Nisbett, 1999). The Yin Yang thinking has had an enormous impact on "Chinese philosophies, martial arts, medicine, science, literature, politics, daily behavior, beliefs, thinking, and other arenas for thousands of years” (Lee, 2000: 1066).

The Yin Yang philosophy suggests that there exists neither absolute black nor absolute white; every universal phenomenon embraces paradox and change. Yin and Yang "cannot survive without each other, and they complement each other, depend on each other, exist in each other, give birth to each other, and succeed each other at different points in time” (Fang, 2005-2006: 76). Yin Yang can be summarized in terms of three principles: "1. Yin and Yang coexist in everything, and everything embraces Yin and Yang. 2. Yin and Yang give rise to, complement, and reinforce each other. 3. Yin and Yang exist within each other and interplay with each other to form a dynamic and paradoxical unity” (Fang, 2012a: 34). 


\section{Box 2 Yin Yang}

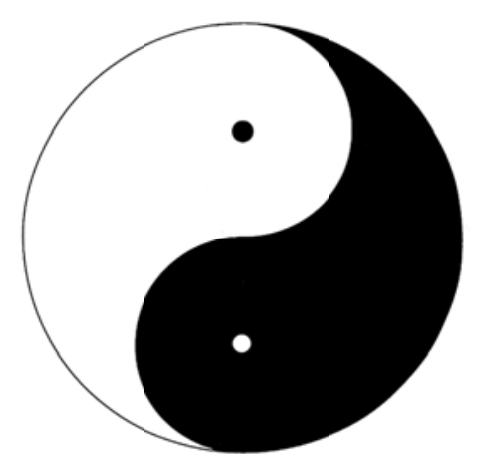

“The Yin Yang symbol...is denoted by a circle divided into two equal halves by a curvy line, one side of which is black (Yin) and the other white (Yang). According to the Yin Yang philosophy, all universal phenomena are shaped by the integration of two opposite cosmic energies, namely Yin and Yang. Yin represents the 'female' energy, such as the moon, night, weakness, darkness, softness, and femininity; while Yang stands for 'male' energy, such as the sun, day, strength, brightness, hardness, and masculinity. The white dot in the black area and the black dot in the white area connote coexistence and unity of the opposites to form the whole. The curvy line in the symbol signifies that there are no absolute separations between opposites. The Yin Yang principle thus embodies duality, paradox, unity in diversity, change, and harmony, offering a holistic approach to problem-solving” (Fang, 2012a: 31-32).

The Yin Yang thinking differs from the Western dialectical thinking (e.g. by Friedrich Hegel, Karl Marx, Georg Simmel, and so on) although both have paradox as a central construct. One fundamental difference is that the former sees paradox as interdependent opposites whereas the latter sees paradox as exclusive opposites (Chen, 2002). The Yin Yang principle views "opposites [as] containing within them the seed of the other and together forming a dynamic unity” (Chen, 2002: 184) over time. Yin Yang has “3-in-1", involving not only dialectical thinking (e.g. How culture embraces paradoxes) but also holistic thinking (e.g., How culture is understood holistically) and dynamic thinking (e.g., How culture evolves over time).

The Yin Yang thinking reveals the ancient Chinese fascination of change as the most fundamental principle of the universe (Chen, 2008) as discussed in the Chinese classic I Ching (or Book of Change) and Tao Te Ching. Some suggested that Yin Yang may be traced even beyond the Chinese context. Similar ideas in the form of ancient totemic beliefs and shamanism have been shared among cultural groups along the Pacific Rim including ancient Chinese, native Americans, and native Mexicans (Lee \& 
Wang, 2003; Wang \& Song, 2007). However, the Yin Yang thinking seems more salient in Chinese culture. In Chinese daily language there are numerous Chinese concepts that are made up of two contradictory sub-concepts to give these concepts a holistic, dynamic, and dialectical meaning. For example, the word “thing” is called dongxi (东西) in Chinese; dong (东) means east and $x i$ (西) means west. Similarly, the word “how much” is duoshao (多少); duo (多) means more and shuo (少) means less. Probably the mostly used Chinese word in leadership training sessions is weiji (危机 “crisis”); wei (危) means danger and ji (机) means opportunity.

Yin Yang has been introduced to the cross-cultural debate (Fang, 1998, 2003, 2005-2006, 2010, 2012a). Culture is perceived as "possessing inherently paradoxical value orientations, thereby enabling it to embrace opposite traits of any given cultural dimension. ...[P]otential paradoxical values coexist in any culture; they give rise to, exist within, reinforce, and complement each other to shape the holistic, dynamic, and dialectical nature of culture. Seen from the Yin Yang perspective, all cultures share the same potential in value orientations, but at the same time they are also different from each other because each culture is a unique dynamic portfolio of self-selected globally available value orientations as a consequence of that culture's all-dimensional learning over time” (Fang, 2012a: 25). If we use “+Vi” [i $=1,2,3, \ldots \mathrm{n}]$ and "-Vi" $[\mathrm{i}=1,2,3, \ldots \mathrm{n}]$ to symbolize various paradoxical value orientations, the Yin Yang perspective on culture suggests:

Proposition 1: If there exist $\{$ “+V1”, “+V2”, “+V3”, . . “+Vn” $\}$ in a culture, $\{$ “-V1”, “-V2”,”V3”, ... “-Vn”\} can coexist in the same culture depending on the situation, context, and time.

Proposition 2: To guide action in a given context at a given time, human beings choose the most relevant value(s) from the full spectrum of potential value orientations ranging from \{“+V1”,”+V2”, “+V3”, . . “ “+Vn”\} to \{“-V1”, “-V2”, “-V3”, . . “-Vn”\}.

Proposition 3: In a culture in a particular context at a particular time some values $\{$ “+V1","+V2", “+V3”, . . “+Vn” $\}$ can be promoted, while other values $\{$ “-V1”, “-V2”,”-V3”, . . “-Vn” $\}$ can be suppressed, thus resulting in a unique value configuration.

Proposition 4: Each culture is a unique dynamic portfolio of self-selected globally available value orientations ranging from $\{$ “+V1", “+V2”, “+V3”, . . . “+Vi” $\}$ to $\{$ “-V1”, “-V2”,”-V3”, . . “-Vi” $\}$ as a consequence of the culture's all-dimensional learning over time.

The dominant cross-cultural paradigm (e.g., Hofstede, 1980, 1991, 2001) defines culture as a stable phenomenon whose value position is fixed over time along various cultural dimensions, thereby making cultural differences an absolute and permanent phenomenon. By contrast, the Yin Yang perspective posits that all cultures share the exact same cultural value potentials; it is the situation, context, and time that make certain cultural values more salient than others. Therefore, cultures are both similar to and different from each other. From the Yin Yang perspective "human beings, organizations, and cultures intrinsically embrace paradoxes for their sheer existence and healthy development. Culture is "both/and" (see Endnote 2) instead of "either/or." We are both Yin and Yang, feminine and masculine, 
long-term and short-term, individualistic and collectivistic, monochronic and polychronic, and highcontext and low-context, depending on situation, context, and time” (see, Fang, 2003: 363; Fang, 20052006: 77).

\section{CHINESE CULTURE: PARADOX AND CHANGE}

By embracing Chinese, foreign, traditional, and modern elements, Chinese culture is a typical example of the Yin Yang thinking. Traditionally, three different philosophical traditions have shaped Chinese culture in a substantial way: Confucianism, Taoism, and Buddhism. Confucianism and Taoism are 2500 years old indigenous Chinese philosophies: in a few words, Confucianism deals with human relationships and how to handle them, whereas Taoism is about how to live one's life in harmony with nature. Imported to China from India around $100 \mathrm{AD}$, Buddhism focuses on the other hand on how to handle relationships between one's mortal and immortal worlds.

To most Chinese people Confucianism, Taoism, and Buddhism are philosophical teachings instead of religions. This unique characteristic of Chinese culture allows the Chinese to selectively follow all the three teachings, instead of sticking to just one of them, to enrich their life, although these teachings compete and even contradict each other in many respects. While, for instance, Confucianism shows people how to do things, Taoism teaches you how to "act without acting" (Wu Wei or "actionless activity”, "letting-go", “doing nothing”). Furthermore, while Confucianism and Taoism remain pragmatic this-worldly philosophies, the doctrine of "reincarnation" that characterizes Buddhism in turn allows Chinese people to see the relationships that exist between their pre-life, present-life and after-life. Thus, by embracing a variety of different teachings, Chinese behavior can be considered as intensely practical, paradoxical, and embracive.

China and Chinese culture has been studied extensively in terms of traditional Chinese cultural (mostly Confucian) values (e.g., Bond \& Hofstede, 1989; Child, 1990, 1994; Fang, 1999; Lieberthal \& Oksenberg, 1986). For example, guanxi, face, thrift, family, rule by man, respect for age and hierarchy, long-term orientation, tradition, etc. have dominated the debates. However, it is worth noting that today's China differs from both ancient China and Mao's China on the very point that the age of globalization, FDI, and Internet has exposed the Chinese society in direct and almost synchronized contact with foreign concepts, cultures, and lifestyles in an unprecedented way. "As cultural groups increase their interactions and dependencies, every one of them will have to change some of their beliefs and behaviors" (Naylor, 1996: 208). Indeed, "change” is found to be the most important keyword that foreign managers tend to use when describing Chinese culture and Chinese business behaviour since 1978 when China’s “open-door” policy was implemented (Fang, Worm, \& Tung, 2008).

However, despite the very dramatic and rapid changes that have occurred in virtually all aspects of Chinese society Faure and Fang (2008: 194) have observed that "China seems to have never given up its single most important cultural characteristic, the ability to manage paradoxes”. Through the examination of eight pairs of paradoxical values in business and social contexts, the authors have argued that Chinese 
culture has undergone significant change. However, "change” occurs not in terms of old values being replaced by new values but rather that contradictory values coexisting more and more visibly in today's Chinese society. In other words, "in terms of the thinking process, modern Chinese society remains anchored to the classical Yin Yang approach” (Faure \& Fang, 2008: 194). The eight paradoxical values identified by Faure and Fang are presented briefly below:

Guanxi vs. Professionalism. Guanxi (关系 interpersonal relationships, personal connections) plays a fundamental role in the conduct of business in Chinese (Luo, 2000) since nothing can be done in Chinese society without guanxi (Davies, Leung, Sherriff, \& Wong, 1995; Redding, 1990). However, if guanxi predominates, rampant corruption may become widespread and affect economic development (Fan, 2002). To foster economic reform, China has adopted and emphasized the importance of the principles of meritocracy and open competition: this has slowly but surely stimulated managers to base their success on professional abilities and not merely on guanxi. Consequently, today's Chinese business culture relies increasingly on a mixture in which guanxi and renqing (人情 personal feeling; personal favor) are counterbalanced by high degrees of professionalism. Thus, conducing successful business in today's China demands both personal relationships (guanxi) and professional abilities (能力 nengli).

Face vs. Self-expression. Freedom, self-expression, and quality of life are some of the values that are fostered by economic growth (Inglehart \& Welzel, 2005; Leung, 2006). Although Chinese people are traditionally face-conscious, reserved in their display of emotions and indirect in their communication (Gao, et al, 1996), professionals of today's China have started to increasingly adopt a quite different behaviour so as to face intense global competition. Thus, while face and humility are still valued, Chinese professionals now tend to project confidence and openness. This is exemplified in a highly publicized advertisement from China Mobile, the world's largest mobile phone operator, in which a confident Chinese manager speaks into his mobile phone with the text displaying “I can!” (我能 Wo neng!) (Faure \& Fang, 2008).

Thrift vs. Materialism. Identified as one of the attributes of Confucian Dynamism (Bond \& Hofstede, 1989), thrift is still a highly valued virtue in today's China. Yet, with the enormous economic growth that has characterized the country for three consecutive decades, the rising living standards, and the consequent wider availability of consumer goods, a hedonistic lifestyle has also started to emerge among a growing segment of China's population. Consequently, foreign luxury brands such as Rolex, Dior, Gucci, Channel, Louis Vuitton and Armani have found in China a ready and fertile market. Put another way, “The philosophy is 'enjoy life today' against the old Chinese custom of saving, saving, saving” (China Luxury, 2007).

Family vs. Individuation. Family has been and still is the basic unit of Chinese society, in so much as sterility was traditionally viewed as the biggest moral crime. Today, choosing to have children at a later age or not to have children at all is no longer a source of shame and gossip in the cities, as evidenced by the growing number of Chinese 'double income no kids' (DINK) families. Young Chinese managers, and in particular those born after 1980 (often referred to as “post-80” (80 后 balinghou), tend 
to give priority to their personal goals, thus suggesting a more individualistic orientation to life (Zhang, 2007). Nowadays, Chinese society allows people to pursue their own interest as well as that of their organization, something that contributes to the emergence of a paradoxical behaviour which emphasizes both personal pursuit (个人追求 geren zhuiqiu) and dedication to the organization and society (奉献 fengxian).

Rule by man vs. Rule of law. Chinese society has traditionally been governed by the rule by man rather than by the rule of law. In this light, laws are viewed as something to be circumvented and/or adapted to suit the rule by man, while legalism has never played a powerful role in society. However, with the opening of China to foreign investment, the need to establish a legal framework has emerged. This has affected, for instance, the way lawyers are viewed in society: considered outcasts during the Cultural Revolution (1966-1976), lawyers are now highly valued in China, since Chinese enterprises need legal experts to conclude commercial contracts and conduct international business negotiations. A further example of China's increased respect for legal practices is the China's New Labor Contract Law that came into effect on January 1, 2008, and which aims to improve employees' working condition and welfare.

Respect for age vs. Meritocracy. Traditionally, the father is the final decision maker in the Chinese family. Nowadays, however, children often earn substantially more than their fathers. This new economic reality challenges the traditional Chinese hierarchy and the unquestioned authority of the father, and affects everyday-life behaviours and value orientations. This means, for examples, that it is now considered normal for the junior member of the family to pay the bill when the family eats out (Faure \& Fang, 2008). While seniority is still valued, it is now counterbalanced by a growing sense of efficiency, competitiveness and newness, especially in economic activities. According to Hurun Report Inc. "the average age of Chinese millionaires is 39, whereas in the United States or Europe, the figure is over 50” (China Daily, 2011: 16).

Long- vs. Short-term orientation. Influenced by the Yin Yang thinking, Chinese culture has traditionally been both long- and short-term oriented. This paradox ha been further accentuated by globalization. A major bone of contention between the partners to a Sino-foreign joint venture often relates to this dimension. In the past, when a joint venture first made a profit, the Western partner usually wanted to re-invest that profit in the company, whereas the Chinese party wanted to cash out the profits. Nowadays, on the other hand, Chinese firms are now increasingly willing to re-invest for longterm success. This has become a driving force in the increasing internationalization of Chinese companies (Faure \& Fang, 2008). Fang's 2001 case study shows that even in time of conflict, the Chinese party still aims to maintain good business relationship in the long run.

Tradition vs. Modernity. In today's Chinese society, modern and traditional values and practices coexist. On the one hand, China's recent successful transformation depends upon its effective utilization of FDI, new technology and professional management. From this perspective, people now tend rely on modern approaches and consider them potentially successful. The “scientific development concept” (科 学发展观 kexue fazhanguan) is advocated by China’s leadership. However, neither Marxism nor 
Western positivism and modern MBA education have succeeded in completely eradicating traditional Chinese practices/values. Although harshly criticized in China in the 1910s and later under Mao's regime, for instance, Confucianism, is still considered a great moral code that guides action. From such a perspective, today's Chinese may be called a 'traditionally modern' or 'modernly traditional' society.

\section{CHINESE COMMUNICATION CHARACTERISTICS}

Chinese communication has long been called a high context communication (Hall, 1976). This view has been reinforced by the theorizing of Chinese culture as a collectivist culture (Hofstede, 1980; Pratt, 1991). Chinese communication characteristics are described as a product of the collectivist-oriented Confucian cultural values in the following famous five-point model (Gao et al, 1996; Gao \& TingToomey, 1998): Implicit communication (含蓄 hanxu), listening-centered communication (听话 tinghua), polite communication (客气 keqi), insider communication (自己人 zijiren), and face-directed communication (面子 mianzi). This dominant scholarship has received increasing critiques in recent years. Chen (2009b: 402) pointed out that "most researchers blindly treat Chinese as being collectivistic and US Americans as being individualistic without considering the internal variations of a culture. This tendency is problematic and can be dangerous, because it may misinform the results of research”. Fang and Faure (2011) identified its two weaknesses in the famous five-point model of Chinese communication characteristics: First, whereas the model gives importance to Confucian cultural values (e.g., relationship, face, politeness, codes of etiquette, etc.), the paradoxical and changing nature of Chinese culture has been neglected. Next, the model does not reflect the impact of the changing institutional and cultural contexts in China on Chinese communication characteristics. Fang and Faure (2011) improved the existing five-point model of Chinese communication characteristics (Gao et al, 1996; Gao \& Ting-Toomey, 1998) by suggesting the following framework that involves five pairs of contradictory Chinese communication characteristics.

Implicit communication vs. Explicit communication. Implicitness is a feature of Chinese communication. According to Lao Tzu, the founder of Taoism: "The Tao that can be told of is not the eternal Tao; The name that can be named is not the eternal name” (Chan, 1963: 139). Implicitness traditionally permeates all aspects of Chinese life, as suggested by Fung's statement (1966: 12) "Suggestiveness, not articulateness, is the ideal of all Chinese art” (Fung, 1966: 12) and by the following Chinese proverb: “It is the bird ahead of the flight that gets shot the first” (枪打出头鸟 qiang da chu tou niao). Yet, the country's rapid economic growth and the increasing demand for expressive branding and professional performance have radically challenged the traditionally implicit communication style. In today's Chinese society, keeping a low profile is no longer a must in all situations. Businesspeople now tend to show their ability much more explicitly than they would have done in the past when "Not available” (meiyou 没有) was a standardized answer. The China Mobile manager’s example (我能 Wo neng!) discussed above also illustrates this point. Presentation techniques, signature design, and attractive CV writing have rapidly become booming business areas. To some extent, today's Chinese 
managers adopt a more direct communication style than in the past. The theme song for "Super Girls" (a Chinese version of American Idol) competition in China in 2005, unprecedented in Chinese TV history, was “If you want to sing, just sing” (想唱就唱 Xiang chang jiu chang). The 21-year-old music girl student Li Yuchun who won the competition was certainly favored by her boy-looking appearance, selfconfident attitude, unconventional clothing, and explicit communication style (Fang, 2010). Li is a cool example of differentiation strategy which mirrors the Chinese society's increasing interest in branding (品牌 pinpai) and image promotion. Hairstyling and clothing are also important means of differentiation and explicit ways to assert one's personality. In the past, Chinese people used to keep their hair black. Nowadays, in Beijing, Shanghai, Guangzhou and Shenzhen it is increasingly common to find a woman between 20 and 40 years old whose hair is died brown, auburn, chestnut, and even sometimes blond (Faure \& Fang, 2008).

Listening-centred communication vs. Speaking-centred communication. In Chinese culture "good children” (好孩子 hao haizi or 乘孩子 guai haizi) are the ones who “listen talks” (tinghua) and do not interrupt (插嘴 chazui) (Gao \& Ting-Toomey, 1998). Speaking is traditionally associated with seniority. In contemporary times the "speaking taboo" is dictated also by the Chinese Communist discipline, which has favored the emergence of the common belief "Disaster comes out of the mouth" (Li, 1994: 127). Nowadays, China is much more diversified than in the past: the family or even personal interests are now occupying an increasingly important place in people's professional lives (Faure, 2008), in so much as following the Party's ideology is no longer the priority in society. China's market-oriented economy has empowered younger generations to have their voice heard and to show their talents. Furthermore, the "one child per family" policy has produced "Little Emperors" and "Little Empresses" who tend to dominate the family’s speaking arena, whereas parents and grandparents are now more and more relegated to the listening side. Unlike in the past, in Chinese university classes and in executive training programs it is now commonplace to ask challenging questions to professors or trainers.

Polite communication vs. Impolite communication. The Chinese concept of politeness is deeply rooted in the Confucian notion of self and harmonious relationships with others and regulated by $l i$ (propriety, rules of conduct). In terms of politeness, Chinese people seem to traditionally adopt different ways of communication according to the social group they are interacting with. From this perspective, three groups can be identified, each of which implies a different communication style. The first group is the core family: communication with this group is quite direct and does not entail much keqi (wellmannered politeness). The second group includes friends: communication with this group is most of the times quite keqi or even extremely keqi. The third group, namely that of strangers, implies brief and functional communicative exchanges. Despite these traditional differences, however, today's market economic development in China has given rise to many opposite behaviors. In order to face competition, for instance, today's taxi drivers, clerks, shopkeepers, waitresses now tend to adopt a very polite communication style, thus abandoning their traditionally detached attitude towards strangers. At the negotiation table, when trust between the negotiation parties has been established, the Chinese negotiator will often behave as a "gentleman", that is speaking in polite, respectful and "win-win" terms. However, when trust is low, the same Chinese negotiator will behave as a "strategist", thus adopting 
tough tactics and a direct communication style to win over the counterpart (Fang, 1999, 2006). The Chinese language contains two contradictory terms/roles that are often used in a commercial context: junzi (君子“Gentleman”, an educated, cultivated, polite, moral and good person) and xiaoren (小人 "Small man", an uneducated, impolite, immoral and mean person). When circumstances require concluding a business deal by signing a detailed written contract, Chinese businesspeople are often likely to say: “Sorry, let us be small men first, gentlemen next” (对不起, 让我们先做小人, 后做君子 Xian zuo xiaoren hou zuo junzi).

Insider-oriented communication vs. Outsider oriented communication. Chinese communication is described as insider-oriented communication (Gao et al, 1996). Chinese society is a "low trust" society where trust is high within the family/kinship border but low outside (Fukuyama, 1995; Lin, 1939). The Chinese tend to engage in communication with "insiders", namely, the people they know directly or through a trusted middle person but they rarely speak to "outsiders", namely, the people they do not know (Gao \& Ting-Toomey, 1998). Decades of Chinese Communism further compounds this issue by drawing another insider vs. outsider demarcation line in terms of Party membership and internal regulations. Today, the traditional insider vs. outsider divide is being challenged in the context of rapid economic development in China in the age of globalization, FDI, and Internet. Driven by extreme economic interests, some individuals can go as far as to cheat their own friends. This phenomenon of making unethical use of insider-communication for one’s own economic interest is called shashu (杀熟 "killing the acquaintances") (Faure \& Fang, 2008), which makes many Chinese people cautious when communicating even with their "insiders". Turning to professional "outsiders" (even non-Chinese nationals and/or organizations) for help to meet the company's goal in the marketplace is definitely not seen as improper action in today's China. Communicating with unknown "outsiders" through the Internet, email, Skype, MSN, QQ, boke (博客), and weibo (微博) is also commonplace. Internet banking involving online business to business (B2B) transactions and online credit card payment, which were unknown to most Chinese people just a decade ago is now enjoying tremendous growth. Internet dating (网恋 wanglian) in China is also emerging as a major alternative to traditional dating forms often organized through friends, colleagues, and/or village matchmakers.

Face-directed communication vs. Face-undirected communication. Chinese communication is face-directed communication (Gao et al, 1996). Rooted in Confucianism, Chinese communication is oriented to saving face and caring about the face of others. This is traditionally by controlling one's feelings, appearing humble, avoiding overt disagreement and even hiding competition. Despite this, however, a "thick face" or "faceless" attitude (Chu, 1992) is also present in Chinese communication: this opposite behaviour derives from Taoism, which postulates that having the courage to lose face can make one psychologically stronger and more mature afterwards. According to the Taoist principle, the best strategy to cope with disgrace is not to stand firm to save your face (a Confucian virtue) but to "run away" to save your life in order to come back later on. This tactic is well illustrated in the Thirty-Six Stratagems discussed by Fang (1999). Traditionally, Chinese culture does not allow to talk about body, sex and gender issues in public discussions. The word "sexy” (性感 xinggan) did not exist in everyday 
Chinese language. Being "sexy" was synonymous with being "shameless" and having a "hooligan” or bu yaolian (不要脸) behavior. In line with this orientation, no kisses are given when people meet or leave: those who do so are often regarded as diulian (丢脸 face-losing). A light-clothing woman would not be viewed as a decent woman but as a bu yaolian (having no face; not morally suitable). However, in today's Chinese culture, there is a growing tendency to accept body, sex and gender issues in communication. Nowadays, Chinese media no longer ban open discussion on sexuality, nor even on homosexuality. In Chinese Internet slang, the word “comrades" (同志 tongzhi) often means "homos" (同性恋 tongxinglian). The term “sexy” is increasingly received as a commonly used adjective. While, in the past, cohabitation (同居 tongju) prior to marriage was considered a social taboo, pre-marriage tongju is now no longer socially stigmatized, especially in larger cities. Today, the adult products sector is among China's most rapidly growing market segment. Expressing "freedom through sex" (Beech, 2006) can be viewed as a way to challenge the traditional repression of self-expression (Faure \& Fang, 2008).

\section{CONCLUSION}

This chapter introduced a Yin Yang (holistic, dynamic, and dialectical) approach to understanding the complexity and richness of Chinese culture and communication. At the core of the analysis is the vision to capture paradox and change in today's Chinese society. "Culture is therefore not a situation-free, context-free, or time-free construct, but rather is embedded in situation, context, and time” (Fang, 2012a: 35). The discussions in this chapter are made at the national level. To manage successfully in China it is important to fine-tune Chinese culture and behaviour at the regional level (Cui \& Liu, 2000; Fang, 2005; see also Box 3), and so on.

Future research should give importance to conditional factors, for example trigger events (see Kim, 2007; Osland, Bird, \& Gundersen, 2010) and their dynamic relationships with the ups and downs of Chinese cultural values over time and variations of Chinese intracultural and intercultural communication patterns. There is a need to study, for example, under what situation, context, and time Chinese professionals behave paradoxically and how to respond effectively to such paradox with a view to maintaining long-term business relationships between interacting organizations and individuals.

Understanding the paradoxical and dynamic nature of Chinese culture and communication is the key to conducting successful business relationships with China. Intercultural experts commonly advise people dealing with the Chinese to dress formally, behave cautiously, use an indirect communication style, display no genuine sentiment, and show a poker face. Such advice is not completely wrong. Yet, following it without carefully considering the situation, context, and time in which business relationships take place can in many cases lead to inappropriate outcomes. As discussed in this chapter, the Chinese are a philosophically "both/and" folk. When they conduct business, they not only do it in formal conference rooms and in office times, but often prefer informal (e.g., beyond office) settings such as restaurants, teahouses, karaoke bars, golf courses, and most recently mountaineering and sailing 
routes. These informal gatherings are at least as important as the formal meetings for developing business relations in China, in which building trust relationships is highly valued. For such a purpose, sightseeing, sporting, singing, and drinking collectively are essential tools: on these occasions, those who keep dressing formally, behaving cautiously, speaking indirectly, displaying no genuine sentiment, and showing a poker face would most probably miss the chance to conclude the deal. Put another way, the Yin Yang perspective on culture suggests that managers should approach cultural differences without being frightened by them. Given the situation, context, and time, outsiders can turn into insiders as much as bad luck can turn into good luck. More importantly, cultural differences, cultural clashes, cultural collisions, and even cultural shocks should be viewed in a proactive and positive way, since they can foster cultural learning, change, innovation, and creativity (Fang, 2012b).

\section{BOX 3 Generalized characteristics associated with Chinese from Beijing, Shanghai, Guangzhou/Shenzhen and select cities in Western China (Tung, Worm, \& Fang, 2008: 63)}

Beijing (capital city, center of political power in the country):

- Politically-oriented-everyone talks about politics

- Bureaucratic - given the prevalence of state-owned enterprises (SOEs) in Beijing and surrounding areas, people tend to be more bureaucratic

- Emphasis on integrity — people place more emphasis on trust and honesty in business dealings

- Highly educated-many of the bureaucrats are highly educated

- More relationship-focused

- More fluid perception of time

- Face comparatively more important

- More holistic in approaching issues

- Focus on general principles

- More diversified cultural life

- More direct and straightforward

Shanghai (commercial center):

- Business savvy - they are known for their business acumen

- Bottom-line oriented

- Focus on details - they perform due diligence before meetings and because of this, some people find it difficult to transact business with Shanghainese because they tend to argue over trivial matters

- Confident and arrogant-because Shanghai has been an important economic center and is the trendsetter in fashion, Shanghainese tend to look down upon people from other cities, referring to them as "villagers"

- Materialistic - Shanghainese are more concerned with brand names and one-upmanship

- $\quad$ More tactical, i.e., calculating

- Greater admiration of the West

- More younger people who have attained high positions

- Obsessed with career progression

Guangzhou/Shenzhen (southern city close to Hong Kong):

- Hard working and highly efficient—in the 1980s, Guangzhou/Shenzhen was recognized for its efficiency in building one entire floor of a skyscraper in three days

- $\quad$ Larger concentration of mass assembly manufacturing

- Entrepreneurial—many prefer to start up their own businesses as opposed to working for established corporations

- Pride in cuisine and more exotic cuisine

- Greater deviation from the norm

- Less concerned about politics

- Identify more closely with Hong Kong

- More concerned with work-life balance issues 
- Superstitious - because many businesspeople there are entrepreneurs, they tend to be more superstitious

- More informal in protocol and clothing

- $\quad$ More risk taking

Western China (cities like Chongqing and Chengdu):

- People’s mentality more like Beijing, Shanghai, and Guangzhou/Shenzhen 5-6 years ago

- More conservative

- More clannish

- More traditional

- Particularistic — emphasize knowing your counterpart first before doing business

- $\quad$ Socializing (eating, drinking, and smoking) is very important

- Greater emphasis on personal relations, i.e., rely on people more than laws or negotiations

- Less experience with international business

- $\quad$ More laid back

- More hardy

- More emotional

- In general, westerners find it more difficult to negotiate/do business here

\section{Endnote:}

1. See "Beyond diplomatic language” (China Daily) http://usa.chinadaily.com.cn/epaper/2012-10/09/content_15803189.htm. Retrieved on 2012-10-22.

2. In this work "both/and" is used not to reject "either/or" but to embrace it by recognizing both conflict and complement inherent in the duality of Yin and Yang.

\section{References}

Beech, H. 2006. Sex, Please: We're young and Chinese. Time Asia (Sunday, January 15). http://www.time.com/time/magazine/article/0,9171,501060123-1149406,00.html Retrieved on 2012-11-16.

Bond, M. H., \& Hofstede, G. 1989. The cash value of Confucian values. Human Systems Management, 8, $195-200$.

Chan, W.-T. 1963. A source book in Chinese philosophy. Princeton: Princeton University Press.

Chen, G.-M. 2008. Bian (Change): A perpetual discourse of I Ching. Intercultural Communication Studies, 17(4): 7-16.

Chen, G.-M. 2009. Beyond the dichotomy of communication studies. Asian Journal of Communication, 19(4): 398-411.

Chen, J. 2001. Mao's China \& the cold war. Chapel Hill, NC: The University of North Carolina Press.

Chen, M. J. 2001. Inside Chinese business: A guide for managers worldwide. Boston: Harvard Business School Press.

Chen, M.-J. 2002. Transcending paradox: The Chinese “middle way” perspective. Asian Pacific Journal of Management, 19(2/3): 179-199.

Chen, M.-J. 2008. Reconceptualizing the competition-cooperation relationship: A transparadox perspective. Journal of Management Inquiry, 17(4): 288-304.

Child, J. 1990. Introduction: The character of Chinese enterprise management. In: J. Child, M. Lockett (Eds.), Advances in Chinese industrial studies (Vol. 1(Part A), pp. 137-152). Greenwich: JAI Press.

Child, J. 1994. Management in China during the age of reform. Cambridge, UK: Cambridge University Press.

China Daily 2011. Traveling: Report lists travel habits. China Daily Asia Weekly, June 17-23. Page 16.

China Luxury 2007. China http://app1.hkicpa.org.hk/APLUS/0710/p24_29.pdf. Retrieved on 2012-11-16.

Chu, C.-N. 1992. Thick face black heart: The path to thriving, winning \& succeeding. Beaverton: AMC Publishing.

Cui, G., \& Liu, Q. 2000. Regional market segments of China: Opportunities and barriers in a big emerging market. Journal of Consumer Marketing. 17(1): 55-72.

Cooper, J. C. 1990. Taoism: The way of the mystic. Wellingborough, UK: Aquarian Press.

Davies, H., Leung, K. P., Sherriff, T. K., \& Wong, Y. 1995. The benefits of guanxi: The value of relationships in developing the Chinese market. Industrial Marketing Management, 24(3): 207-214.

Fan, Y. 2002. Questioning guanxi: Definition, classification and implications. International Business Review, 11(5): 543-561. 
Fang, T. 1998. Reflection on Hofstede's 5th Dimension: A Critique of "Confucian Dynamism". Competitive paper presented at the Academy of Management Annual Meeting, San Diego, California, August 9-12.

Fang, T. 1999. Chinese business negotiating style. Thousand Oaks, CA: Sage.

Fang, T. 2001. Culture as a driving force for interfirm adaptation: A Chinese case. Industrial Marketing Management, 30(1), 51-63.

Fang, T. 2003. A critique of Hofstede’s fifth national culture dimension. International Journal of Cross Cultural Management, 3(3): 347-368.

Fang, T. 2005. Chinese business style: A regional approach. In A. Macbean \& D. Brown (Eds.), Challenges for China's development: An enterprise perspective: 156-172. London: Routledge.

Fang, T. 2005-2006. From “onion" to "ocean": Paradox and change in national cultures. International Studies of Management \& Organization, 35(4): 71-90.

Fang, T. 2006. Negotiation: The Chinese style. Journal of Business \& Industrial Marketing, 20(1): 50-60.

Fang, T. 2010. Asian management research needs more self-confidence: Reflection on Hofstede (2007) and beyond. Asia Pacific Journal of Management, 27(1): 155-170.

Fang, T. 2012a. Yin Yang: A new perspective on Culture. Management and Organization Review, 8(1): 25-50.

Fang, T. 2012b. Yin Yang is relevant to modern business. Chinese Management Insight (CMI) http://www.iacmr.org/V2/Publications/CMI/EH010801_EN.pdf Retrieved on 2012-11-16.

Fang, T., \& Faure, G. O. 2011. Chinese communication characteristics: A Yin Yang perspective. International Journal of Intercultural Relations, 35(3): 320-333.

Fang, T., Worm, V., \& Tung, R.L. 2008. Changing success and failure factors in business negotiations with the PRC. International Business Review, 17(2): 159-169.

Faure, G.O., \& Fang, T. 2008. Changing Chinese values: Keeping up with paradoxes. International Business Review, 17(2): 194-207.

Fernandez, J. A., \& Underwood, L. 2006. China CEO: Voices of experience from 20 international business leaders. Singapore: Wiley.

Fletcher, R., \& Fang, T. 2006. Assessing the impact of culture on relationship creation and network formation in emerging Asian markets. European Journal of Marketing, 40: 430-446.

Fung, Y.-L. 1966. A short history of Chinese philosophy. New York: The Free Press. (First published in 1948).

Gao, G., Ting-Toomey, S., \& Gudykunst, W. B. 1996. Chinese communication processes. In M. H. Bond (Ed.), The handbook of Chinese psychology (pp. 280-293). Hong Kong: Oxford University Press.

Gao, G., \& Ting-Toomey, S. 1998. Communicating effectively with the Chinese. Thousand Oaks: Sage.

Hofstede, G. 1980. Culture's consequences: International differences in work-related Values, SAGE Publications, Newbury Park

Hofstede, G. 1991. Cultures and organizations: Software of the mind, New York: McGraw-Hill.

Hofstede, G. 2001. Culture's consequences: Comparing values, behaviors, institutions, and organizations across nations, 2nd ed. Thousand Oaks: Sage.

Inglehart, R., \& Welzel, C. 2005. Modernization, cultural change, and democracy: The human development sequence. New York: Cambridge University Press.

Jakobson, L. 1998. A million truths: A decade in China. New York: M. Evans.

Lee, Y.-T. 2000. What is missing in Chinese-Western dialectical reasoning? American Psychologist, 55(9): 1065-1067.

Lee, Y.-T., \& Wang, D.-Y. 2003. Aboriginal people in Taiwan, continental China and the Americas: Ethnic inquiry into common root and ancestral connection. In X. Li \& Z. Pan (Eds.), Taiwan in the twenty-first century: 63-82. Lanham, MD: University Press of America.

Leung, K., \& Bond, M. H. 2004. Social axioms: A model for social beliefs in multicultural perspective. Advances in Experimental Social Psychology, 36: 119-197.

Li, Z. S. 1994. The private life of Chairman Mao. New York: Random House.

Lieberthal, K., \& Oksenberg, M. 1986. Understanding China's bureaucracy. China Business Review, 13(6): 24-31.

Little, A. 1902. The land of the blue gown. London: T. Fisher Unwin.

Luo, Y. D. 2000. Guanxi and business. Singapore: World Scientific.

Naylor, L.L. 1996. Culture and change: An introduction. Westport, CT: Bergin \& Garvey.

Peng, K., \& Nisbett, R. E. 1999. Culture, dialectics, and reasoning about contradiction. American Psychologist, 54(9): $741-754$.

Redding, G. 1990. The spirit of Chinese capitalism. Berlin: Walter de Gruyter. 
Tung, R. L., Worm, V., \& Fang, T. 2008. Sino-western business negotiations revisited: 30 years after China’s open door policy. Organizational Dynamics, 37(1): 60-74.

Wang, D.-Y., \& Song, B.-Z. 2007. Mystery of the Indians. (Yindi'an zhi mi). Beijing: Zhongguo shi dai jing ji chu ban she. (In Chinese).

Zhang, Z. X. (2007). Barriers to organizational harmony: Mismatch between the values of leaders and employees. Peking University Business Review, (1): 24-29.

\section{Questions for this chapter}

1. What is the difference between Yin Yang and Western dialectical thinking?

2. How to understand that Yin Yang in a broad sense embraces even the "either/or" approach?

3. Please discuss a number of Chinese cultural values and their development over the past 100 years.

4. Please find a video clipping (from example from social media) on Chinese culture and communication and make discussions by following the debates in this chapter.

5. How to communicate with the Chinese if you do not know each other? if you are friends, and if you are very close friends?

6. How to handle situations when a good relationship with the Chinese turns sour?

7. Please conduct interviews of an organization doing business with China; use the discussed frameworks in this chapter to analyze the data and answer the research question: How to communicate effectively with the Chinese colleagues/employees/boss?

8. Is the Yin Yang perspective on culture useful for explaining your own culture and behaviour? How and why?

\section{Case study}

In Chinese language/culture, two paradoxical phrases are often used by people to deliver greetings to each other: One is “Gong xi fa cai 恭喜发财” , the other is “Po cai mian zai 破财免灾”. Please answer the following questions with the help of your Chinese-speaking colleagues:

1. What is the meaning of "Gong xi fa cai" and "Po cai mian zai"?

2. What is the philosophical base for these two phrases, respectively?

3. Under what circumstances (situation, context, and time) do Chinese people use these two paradoxical greetings, respectively and simultaneously?

\section{ACKNOWLEDGEMENT}

Many thanks to Marta Guarda, PhD, University of Padova, Italy, who has helped with the editing of this book chapter text. 